\title{
EFFECT OF ANTENATAL LACTATION COUNSELLING AND POSTNATAL LACTATION SUPPORT IN IMPROVING BREASTFEEDING INITIATION RATES AND EXCLUSIVE BREASTFEEDING IN LESS EDUCATED MOTHERS OF RURAL AREA OF CHANDU- BUDHERA
}

\author{
Satya Kiran Kapur1, Yamini², Harish Gupta³, Pawan Kumar 4
}

${ }_{1}^{1}$ Associate Professor, Department of Paediatrics, Faculty of Medical and Health Sciences, SGT University, Budhera, Gurugram, Haryana. 2 Professor and HOD, Department of Surgery, SHKM Government Medical College, Nalhar, Nuh, Haryana.

${ }^{3}$ Senior Resident, Department of Paediatrics, Faculty of Medical and Health Sciences, SGT University, Budhera, Gurugram, Haryana. 4Junior Resident, Department of Paediatrics, Faculty of Medical and Health Sciences, SGT University, Budhera, Gurugram, Haryana.

\begin{abstract}
BACKGROUND

Human breast milk is the best source of nourishment for the human infants. Breastfeeding promotes health and helps to prevent disease. Antenatal lactation counselling and postnatal lactation support have an impact in initiation of breastfeeding immediately after birth and in practicing exclusive breastfeeding for first 6 months of infant's life.

The objective of this study is to study the impact of antenatal lactation counselling and postnatal lactation support to mothers of newborns in improving breastfeeding initiation rates and continuation of exclusive breastfeeding for first 6 months of infant's life as compared to mothers of newborns not provided such counselling.
\end{abstract}

\section{MATERIALS AND METHODS}

For 4 months, 151 mothers of newborns received the usual verbal advice for breastfeeding from hospital staff (Control group). For another 4 months, 155 mothers of newborns received proper antenatal lactation counselling and postnatal lactation support by Paediatric residents and nursing staff trained in lactation counselling (Intervention group).

\section{RESULTS}

95\% of counselled mothers (Intervention group) initiated breastfeeding immediately after birth in comparison to $78 \%$ of noncounselled mothers (Control group). Similarly, 87\% of counselled mothers (Intervention group) practiced exclusive breastfeeding for first 6 months of infant's life in comparison to 19\% of non-counselled mothers (Control group).

\section{CONCLUSION}

Antenatal lactation counselling and postnatal lactation support help in improving initiation of breastfeeding immediately after birth and practicing exclusive breastfeeding for first 6 months of infant's life.

\section{KEYWORDS}

Antenatal Lactation Counselling, Postnatal Lactation Support, Exclusive Breastfeeding, Infant.

HOW TO CITE THIS ARTICLE: Kapur SK, Yamini, Gupta H, et al. Effect of antenatal lactation counselling and postnatal lactation support in improving breastfeeding initiation rates and exclusive breastfeeding in less educated mothers of rural area of ChanduBudhera. J. Evolution Med. Dent. Sci. 2017;6(13):1025-1027, DOI: 10.14260/Jemds/2017/219

\section{BACKGROUND}

Breastfeeding remains the superior form of infant nutriture.[1] The ability to counsel breastfeeding women and a multi-prong approach significantly impact her success in breastfeeding her infant.[2,3,4,5] Results show that all forms of extra support showed an increase in the length of time women continued to breast feed.

Human breast milk is the best source of nourishment for human infants. Breastfeeding promotes health, helps to prevent disease and reduces healthcare and feeding costs. The benefits of prolonged breastfeeding for mother and infant health are documented in vast scientific literature.[6]

Financial or Other, Competing Interest: None.

Submission 06-01-2017, Peer Review 01-02-2017,

Acceptance 06-02-2017, Published 09-02-2017.

Corresponding Author:

Dr. Satya Kiran Kapur,

\#H-40, First Floor, Residency Greens,

(Opposite Unitech Cyber Park),

Sector 46, Gurugram (Gurgaon)-122003, Haryana.

E-mail: kapoorsatyakiran@gmail.com

DOI: $10.14260 /$ jemds $/ 2017 / 219$

The American Academy of Paediatrics recommends exclusive breastfeeding for the first 6 months of infant's life, continuing to 1 year with the addition of complementary foods at 6 months of age.[7]

Exclusive breastfeeding is the most natural and scientific way of feeding the infant in the first 6 months of life. Breastfeeding can contribute to the reduction of mortality and morbidity.[8]

Many mothers in reality do not practice exclusive breastfeeding up to 6 months of infant's life and the main reasons for discontinuing breastfeeding are -

A lack of confidence in their ability to breastfeed,[9,10] breast pain or soreness, perceptions of insufficient milk supply for infant, problems with the infant's suckling or a lack of encouragement from the hospital staff.

Antenatal breastfeeding education and postnatal lactation support provided by the hospital staff (properly trained doctors, nursing staff) improve rates of exclusive breastfeeding up to 6 months after delivery.[11]

Successful breastfeeding depends on the healthcare provider's knowledge of the mechanics of breastfeeding, the evaluation of successful lactation and the interventions required if difficulties develop. 
A 2012 Cochrane review recommended exclusive breastfeeding for the first 6 months of infant's life in both developing and developed countries.

A 2012 review supports the practice of early initiation of breastfeeding that includes skin-to-skin contact between the mother and infant. Skin-to-skin contact is associated with a higher success of breastfeeding in the first one to four months. In addition, it is associated with improved infant homeostasis in the immediate postpartum period as well as decreased crying behaviour.[12]

The mother who is breastfeeding and learning to know her newborn should be surrounded by a supportive caring team of healthcare providers and family members.[13]

\section{Objective}

To study the impact of antenatal lactation counselling and postnatal lactation support in improving breastfeeding initiation rates and continuation of exclusive breastfeeding up to 6 months of infant's life.

\section{MATERIALS AND METHODS}

The study was conducted in maternity section of SGT Hospital, Budhera, District Gurugram, Haryana, India.

Mothers who delivered full-term, healthy, singleton, appropriate for gestational age neonates with a birth weight of $>2.2 \mathrm{~kg}$ were included in the study.

During the period between 11.01.2016 to 10.05.2016, 151 mothers of newborns received the usual verbal advice for breastfeeding and routine follow-up visits for immunisation from hospital staff (Control group).

From 11.05.2016 to 11.07.2016, paediatric residents and nursing staff were trained in lactation counselling.

During the period between 12.07.2016 to 11.11.2016, 155 mothers of newborns received antenatal lactation counselling and postnatal lactation support by paediatric residents and nursing staff trained in lactation counselling (Intervention group).

\section{Exclusion Criteria}

- Mothers or infants admitted in Intensive Care Units.

- Heavily medicated mothers.

- Low Apgar score newborns.

- Infants born with congenital malformations.

- Neonates having respiratory distress.

- $\quad$ Premature Neonates.

Mothers who were not likely to visit Paediatrics OPD for followup.

The mothers of Intervention group were supervised and helped during the first feed and subsequently till discharge. Mothers were counselled regarding the benefits of early and exclusive breastfeeding, proper positioning and attachment, importance of colostrum, frequency of breastfeeding and duration of each feed, breastfeeding related difficulties, diet during lactation during their stay in the antenatal and early postnatal period. They were encouraged to exclusively breastfeed their infants for 6 months and continue breastfeeding along with complementary foods up to 1 year or may be 2 years.

They were advised to visit Paediatrics OPD for follow-up on day $3,7,14,28$ and then monthly visits up to 6 months of infant's life to observe continuation of exclusive breastfeeding up to 6 months of infant's life. During this period, Immunisation and Vit. A solution were administered to the infants.

\section{RESULTS}

Between 11.01.2016 to 10.05.2016, the control group comprising 151 mothers of newborns did not receive antenatal as well as postnatal lactation counselling except routine postnatal verbal advice for breastfeeding from hospital staff.

Between 12.07.2016 to 11.11.2016, the intervention group comprising 155 mothers of newborns received antenatal as well as postnatal lactation counselling from trained paediatric residents and nursing staff.

\begin{tabular}{|c|c|c|c|}
\hline $\begin{array}{l}\text { Sl. } \\
\text { No. }\end{array}$ & & $\begin{array}{c}\text { Control } \\
\text { Group }(n=151)\end{array}$ & $\begin{array}{c}\text { Intervention } \\
\text { Group }(n=155)\end{array}$ \\
\hline & $\begin{array}{c}\text { Mother's } \\
\text { Characteristics }\end{array}$ & & \\
\hline \multirow[t]{5}{*}{1.} & Education & No. $(\%)$ & No. $(\%)$ \\
\hline & $\begin{array}{l}8^{\text {th }} \text { Class } \\
\text { or Below }\end{array}$ & $17(11)$ & $15(10)$ \\
\hline & $10^{\text {th }}$ Class & 41 (27) & 45 (29) \\
\hline & 12th Class & $82(54)$ & $86(55)$ \\
\hline & Graduation & $11(07)$ & $09(05)$ \\
\hline 2. & $\begin{array}{c}\text { Prior } \\
\text { Breastfeeding } \\
\text { Experience }\end{array}$ & $62(41)$ & $61(39)$ \\
\hline \multicolumn{4}{|c|}{ Table I. Characteristics of the Study Population } \\
\hline
\end{tabular}

\begin{tabular}{|c|c|c|c|}
\hline Group & Yes & No & $\%$ \\
\hline $\begin{array}{c}\text { Mothers not counselled } \\
\text { on breastfeeding (n = 151) }\end{array}$ & 118 & 33 & 78 \\
\hline $\begin{array}{c}\text { Mothers counselled on } \\
\text { breastfeeding (n = 155) }\end{array}$ & 148 & 07 & 95 \\
\hline $\begin{array}{c}\text { Table II. Comparison of the Initiation of } \\
\text { Breastfeeding immediately after Birth by the }\end{array}$ \\
Mothers in the Non-Counselled and Counselled Group \\
\hline
\end{tabular}

\begin{tabular}{|c|c|c|c|}
\hline Group & Yes & No & $\%$ \\
\hline $\begin{array}{c}\text { Mothers not counselled } \\
\text { on breastfeeding (n = 151) }\end{array}$ & 30 & 121 & 19 \\
\hline $\begin{array}{c}\text { Mothers counselled } \\
\text { on breastfeeding (n = 155) }\end{array}$ & 136 & 19 & 87 \\
\hline $\begin{array}{c}\text { Table III. Comparison of the Exclusive Breastfeeding } \\
\text { Practiced for First 6 Months by the Mothers in } \\
\text { the Non-Counselled and Counselled Group }\end{array}$ \\
\hline
\end{tabular}

\section{DISCUSSION}

The results of our study show that $95 \%$ of mothers of the counselled group initiated breastfeeding immediately after birth as compared to $78 \%$ of mothers of non-counselled group. In a study by Dhandapany et al[14] in Pondicherry, India, most of the mothers who received antenatal lactation counselling initiated breastfeeding immediately after birth as compared to non-counselled mothers.

Similarly, $87 \%$ of the mothers in our study who were counselled practiced exclusive breastfeeding for first 6 months of their infant's life as compared to $19 \%$ of noncounselled mothers. In a study by Labarere et al,[15] majority 
of mothers of intervention group practiced exclusive breastfeeding as compared to mothers of the control group, though they studied exclusive breastfeeding at 4 weeks instead of first 6 months of infant's life.

\section{CONCLUSION}

Antenatal lactation counselling and postnatal lactation support have definitive role in motivating the mothers for initiation of breastfeeding immediately after birth and practicing exclusive breastfeeding for first 6 months of infant's life.

\section{REFERENCES}

[1] Goldman AS. The immune system in human milk and the developing infant. Breastfeed Med 2007;2(4):195204.

[2] Lellamo A, Sobel H, Engelhardt K. Working mothers of the World Health Organization Western Pacific offices: lessons and experiences to protect, promote, and support breastfeeding. J Hum Lact 2015;31(1):36-9.

[3] Dereddy NR, Talati AJ, Smith A, et al. A multipronged approach is associated with improved breast milk feeding rates in very low birth weight infants of an inner-city hospital. J Hum Lact 2015;31(1):43-6.

[4] Rozga MR, Kerver JM, Olson BH. Prioritization of resources for participants in a peer counseling breastfeeding support program. J Hum Lact 2015;31(1):111-9.

[5] Srinivas GL, Benson M, Worley S, et al. A clinic-based breastfeeding peer counselor intervention in an urban, low-income population: interaction with breastfeeding attitude. J Hum Lact 2015;31(1):120-8.

[6] Kramer MS, Kakuma R. Optimal duration of exclusive breastfeeding. Cochrane Database Syst Rev 2012;15(8):CD003517.
[7] Breastfeeding and the use of human milk. American academy of pediatrics. Work group on breastfeeding. Pediatrics 1997;100(6):1035-9.

[8] Cunha AJ, Leite AM, Machado MM. Breastfeeding and pacifier use in Brazil. Indian J Pediatr 2005;72(3):20912.

[9] Ertem IO, Votto N, Leventhal JM. The timing and predictors of the early termination of breastfeeding. Pediatrics 2001;107(3):543-8.

[10] Taveras EM, Capra AM, Braveman PA, et al. Clinician support and psychosocial risk factors associated with breastfeeding discontinuation. Pediatrics 2003;112(1 Pt 1):108-15.

[11] Su LL, Chong YS, Chan YH, et al. Antenatal education and postnatal support strategies for improving rates of exclusive breast feeding: randomized controlled trial. Br Med J 2007;335(7620):596-612.

[12] Moore ER, Anderson GC, Bergman N, et al. Early skin to-skin contact for mothers and their healthy newborn infants. Cochrane Database Syst Rev 2016;25(11):CD003519.

[13] Jolly K, Ingram L, Khan KS, et al. Systematic review of peer support for breastfeeding continuation: metaregression analysis of the effect of setting, intensity, and timing. BMJ 2012;25:344:d8287.

[14] Dhandapany G, Bethou A, Arunagirinathan A, et al. Antenatal counseling on breastfeeding - is it adequate? A descriptive study from Pondicherry, India. Int Breastfeed J 2008;3:5.

[15] Labarere J, Gelbert-Baudino N, Ayral AS, et al. Efficacy of breastfeeding support by trained clinicians during an early, routine, preventive visit: a prospective randomized, open trial of 226 mother-infant Pairs. Pediatrics 2005;115(2):139-46. 